\title{
Linking greenhouse gas emissions to urban landscape structure: the relevance of spatial and thematic resolutions of land use/cover data
}

\author{
Xia-li Luan · Alexander Buyantuev • Albert Hans Baur • Birgit Kleinschmit • \\ Haijun Wang $\cdot$ Sheng Wei $\cdot$ Maosong Liu $\cdot$ Chi Xu $\mathbb{D}$
}

Received: 27 November 2017 / Accepted: 28 May 2018/Published online: 9 June 2018

(C) The Author(s) 2018

\begin{abstract}
Context Emissions of greenhouse gases in urban areas play an important role in climate change. Increasing attention has been given to urban landscape structure-emission relationships (SERs). However, it remains unknown if and to what extent SERs are dependent on observational scale.

Objective To assess how changing observational scales (in terms of spatial and thematic resolutions) of urban landscape structure affect SERs.
\end{abstract}

Electronic supplementary material The online version of this article (https://doi.org/10.1007/s10980-018-0661-9) contains supplementary material, which is available to authorized users.

X. Luan · M. Liu · C. Xu ( $ه)$

School of Life Sciences, Nanjing University,

Nanjing 210023, China

e-mail: xuchi@nju.edu.cn

\section{A. Buyantuev}

Department of Geography and Planning, University at Albany, SUNY, 1400 Washington Ave, Albany, NY 12222, USA

\section{A. H. Baur}

sustainable AG, Corneliusstr. 10, 80469 Munich, Germany

B. Kleinschmit

Geoinformation in Environmental Planning Lab,

Department of Landscape Architecture and

Environmental Planning, Technische Universität Berlin,

Berlin, Germany
Methods We examined correlations between 16 landscape metrics and greenhouse gas emissions across 52 European cities, through (1) systematic manipulation of spatial and thematic resolutions of the urban land use/cover (ULUC) dataset, and (2) comparison between available standard ULUC datasets with different spatial resolutions.

Results Our analyses showed that the observed SERs significantly depend on both thematic and spatial resolutions of the ULUC data. For the 16 landscape metrics, we found diverse spatial/thematic scaling relations exhibiting monotonic, hump-shaped or scaleinvariant trends. For different landscape metrics, the SERs were strongest at different spatial scales,

H. Wang

State Key Laboratory of Freshwater Ecology and Biotechnology, Institute of Hydrobiology, Chinese Academy of Sciences, Wuhan 430072, China

S. Wei

School of Architecture and Urban Planning, Nanjing University, Nanjing 210023, China

\section{S. Wei}

Jiangsu Institute of Urban Planning and Design, Nanjing 210036, China 
suggesting that there is no consistent scaling relation over those observational scales.

Conclusions SERs are highly sensitive to spatial and thematic resolutions of landscape data. To avoid the problem of 'ecological fallacy,' important caveats should be taken for interpretations based on single landscape metrics. Particular consideration should be paid to metrics that are easily interpretable, predictable in scaling behaviors, and important for shaping SERs, such as PLAND, ED, and LPI. Systematic investigations on scaling behaviors of SERs over well-defined scale domains are encouraged in future studies linking greenhouse gas emissions and urban landscape structure.

Keywords Climate change - Landscape pattern . Landscape metrics $\cdot$ Remote sensing $\cdot$ Scale $\cdot$ Scaling

\section{Introduction}

Fossil-fuel energy has boosted the worldwide socioeconomic development since the Industrial Revolution. However, greenhouse gases (GHGs, such as $\mathrm{CO}_{2}$, $\mathrm{N}_{2} \mathrm{O}, \mathrm{CH}_{4}$, and $\mathrm{SF}_{6}$ ) released from the combustion of fossil fuels have induced a range of serious environmental problems. Currently, anthropogenic GHG emissions are estimated to amount to $\sim 50$ gigatons of $\mathrm{CO}_{2}$-equivalent per year (Pachauri et al. 2014). Such massive emissions have resulted in drastic elevation of GHG concentrations in the atmosphere, cascading to significant changes of global and regional climate (Crowley 2000; Melillo et al. 2014) and profound impacts on ecosystems and human wellbeing (Field and Barros 2014). Urban areas are among the most important sources of GHG emissions. Accounting for only $\sim 3 \%$ of the Earth's land surface (Liu et al. 2014), they are directly or indirectly responsible for more than half of GHG emissions in the world (Hoornweg et al. 2010). Therefore, cutting urban GHG emissions is recognized as the primary goal for mitigating global climate change (Dhakal 2010).

As a fundamental step towards effective actions in reducing urban GHG emissions, it is imperative to identify and understand the physical and socioeconomic drivers of those emissions. Much attention has been paid to socioeconomic factors, such as population density, income, and lifestyle of urban residents (Newman and Kenworthy 1989; Baur et al. 2013, 2015b; Lee and Lee 2014). However, physical properties of urban landscapes can also substantially influence anthropogenic emissions (Norman et al. 2006; Ou et al. 2013). In this context, recent studies have focused on the role of urban spatial structure, giving rise to a general observation that sprawling urban landscape structures, contrasting with relatively compact counterparts, are correlated with higher per capita emissions of air pollutants and GHGs (Borrego et al. 2006; Makido et al. 2012; Baur et al. 2015a). This correlation makes intuitive sense. For example, if urban patches are more scattered in space, residents have to travel longer distances, i.e., commute between home, work place, and amenities, substantially increasing energy consumption of transportation and associated emissions (Anderson et al. 1996; Chen et al. 2011). Such correlation provides an important practical implication, in the sense that urban systems designed with 'optimal' spatial structures could contribute to both air quality improvement and climate change mitigation (Martins 2012; Rodríguez et al. 2016). This idea has given rise to the 'compact city' movement that now receives growing attention worldwide.

Despite this optimization and mitigation opportunity, relationships between urban landscape structure and anthropogenic GHG emissions (hereafter referred to as structure-emission relationships, SERs) remain largely uncertain. One key uncertainty is rooted in the issue of scale. Typically, SERs are commonly scaledependent pattern-process relationships. Depending on the spatial, temporal, or thematic scale, a given SER can be detected as either strong or weak (Turner 1989; Wu 2004). During the past decades, systematic investigations have shown that landscape pattern metrics used to quantify landscape structure are sensitive to spatial scale, in terms of grain size (Turner et al. 1989; Wu et al. 2002; Wu 2004) and spatial extent (Saura and Martinez-Millan 2001; Shen et al. 2004). With the gradual increase of spatial scale, landscape metrics may present linear, logarithmic, hump-shaped, or complex response (e.g., Wu et al. 2002). Similar observations have also been reported for thematic scale, i.e., the number of categories that are distinguished in the land use/cover maps (e.g., Shao et al. 2001; Buyantuyev and Wu 2007). These findings suggest the need for a routine analysis of scale 
dependence of landscape pattern-process relationship. At a minimum, observations, experiments, or models should be conducted at multiple, at least three, relevant scales (e.g., Wu et al. 2000; $\mathrm{Li}$ and $\mathrm{Wu}$ 2006). Yet, explicit scale analyses are still limited for many pattern-process relationships.

Reasonably, the scale issue is important for SERs. So far, it remains unclear how SERs would respond to changes in observational scales. To our knowledge, we conducted the first systematic scaling analysis (in terms of changing data resolutions) of SERs in this study by focusing on GHG emissions across 52 selected European cities. We used two scaling approaches. First, we conducted systematic manipulation of spatial and thematic resolutions of an urban land use/cover (ULUC) dataset. Second, we compared several available and commonly used ULUC datasets with inherently different spatial resolutions. The second approach addresses the concern that previous studies tended to arbitrarily select land use/cover data for quantifying landscape pattern-process relationships, including SERs. However, it remains to be tested whether these datasets of different resolutions can lead to different conclusions. Our specific goal was to assess if, and to what extent, spatial and thematic resolutions of data on urban spatial structure affect observed SERs. We pursue a better understanding of influencing factors of urban GHG emissions with the objective to provide valuable suggestions for urban planning and management seeking GHG mitigation.

\section{Materials and methods}

\section{Study cities and data}

We used a unique GHG emission dataset compiled by Baur et al. (2015a) to analyze the SERs for 52 cities across Europe. This dataset combined comparable GHG information per capita during 2007-09, including emissions from both residential and non-residential sources, and corrected for the between-nation variation of energy production methods (Supplementary Table 1, see Baur et al. 2015a for detailed information).

For all studied cities, we collected 6 publicly available datasets that provide information on land use/cover on a continental or global scale, with spatial resolutions ranging from 10 to $1000 \mathrm{~m}$ (Table 1). These datasets were produced from various data sources including remotely sensed images, topographic maps, population distribution data, and navigation data. Of those, the Urban Atlas (UA, $10 \mathrm{~m}$ resolution) dataset contains information on (European) urban areas only. The estimated accuracy of ULUC mapping ranges from circa 70 to $100 \%$. For the multi-temporal CORINE land cover (100 m resolution) and GlobCover (300 m resolution) datasets, we selected data for the year 2006 and 2009, accordingly, to provide for the closest temporal conformity with the GHG emission data. Although the temporal coverage of these ULUC datasets (ranging between 2003 and 2010) does not completely coincide with that of the analyzed GHG, they are useful for our study, as no significant change is expected in the overall urban layout of the much-developed European cities during this time period. Indeed, a comparison between the ESA CCI land cover 2003 and 2010 data shows that $>92 \%$ of the urban areas remained stable for 50 out of the 52 studied cities.

The UA and CORINE are different from the other ULUC datasets in the sense that they have the fourlevel hierarchical classification system, corresponding to four thematic scales (Fig. 1). In contrast, the other four ULUC datasets have only one single ULUC class. Another important difference between these datasets pertains to the definition of urban area. For the four datasets other than UA and CORINE, urban areas, labeled 'Artificial surfaces and associated areas' or 'Urban,' respectively, are referred to as non-vegetated features that are made by humans. In contrast, for the UA and CORINE datasets, urban lands are defined as 'Artificial Surfaces' encompassing non-sealed green urban areas dominated by vegetation. We thus excluded such green urban areas from the UA and CORINE data (class 1.4.1) to make them consistent with other ULUC datasets. To avoid any confusion, in this study, we use the term 'urban' to refer to those that are dominated ( $>50 \%$ in cover) by non-vegetated, human-made elements (also defined as 'built-up areas' in Liu et al. 2014).

\section{Landscape metrics}

We selected 16 landscape metrics to characterize urban landscape structure. Of those, 9 metrics were previously defined as 'urban structure indicators' by 
Table 1 Urban land use/cover datasets used for spatial scaling analyses

\begin{tabular}{|c|c|c|c|c|c|c|c|}
\hline Dataset & Data producer & $\begin{array}{l}\text { Nomenclature } \\
\text { of urban area }\end{array}$ & $\begin{array}{l}\text { Spatial } \\
\text { resolution }\end{array}$ & $\begin{array}{l}\text { Temporal } \\
\text { coverage }\end{array}$ & $\begin{array}{l}\text { Data source for } \\
\text { dataset production }\end{array}$ & $\begin{array}{l}\text { Accuracy } \\
\text { for urban } \\
\text { area }\end{array}$ & References \\
\hline Urban Atlas & $\begin{array}{l}\text { European } \\
\text { Environment } \\
\text { Agency } \\
\text { (EEA) }\end{array}$ & $\begin{array}{l}\text { Artificial } \\
\text { Surfaces }\end{array}$ & $\begin{array}{l}10 \mathrm{~m} \\
(1: 10,000)\end{array}$ & $\begin{array}{l}2006 \\
\quad( \pm 1 \text { year })\end{array}$ & $\begin{array}{c}\text { Remotely sensed } \\
\text { data (EO data), } \\
\text { Topographic } \\
\text { maps, COTS } \\
\text { navigation data }\end{array}$ & $>=85 \%$ & $\begin{array}{l}\text { http://www.eea. } \\
\text { europa.eu/ } \\
\text { data-and- } \\
\text { maps/data/ } \\
\text { urban-atlas } \\
\text { EEA (2010) }\end{array}$ \\
\hline GlobeLand30 & $\begin{array}{l}\text { National } \\
\text { Geomatics } \\
\text { Centre of } \\
\text { China } \\
\text { (NGCC) }\end{array}$ & $\begin{array}{l}\text { Artificial } \\
\text { Surface and } \\
\text { Associated } \\
\text { Areas }\end{array}$ & $30 \mathrm{~m}$ & 2010 & $\begin{array}{l}\text { Remotely sensed } \\
\text { data (Landsat } \\
\text { TM/ETM + } \\
\text { HJ-1 } \\
\text { multispectral } \\
\text { images) }\end{array}$ & $>80 \%$ & $\begin{array}{l}\text { http://www. } \\
\text { geodoi.ac.cn/ } \\
\text { WebCn/doi. } \\
\text { aspx?Id=163 } \\
\text { Chen et al. } \\
(2015,2016)\end{array}$ \\
\hline $\begin{array}{l}\text { CORINE } \\
\text { Land Cover } \\
\text { (CLC) } \\
2006 \\
\text { version } \\
18.5 .1\end{array}$ & $\begin{array}{l}\text { European } \\
\text { Environment } \\
\text { Agency } \\
\text { (EEA) }\end{array}$ & $\begin{array}{l}\text { Artificial } \\
\text { Surfaces }\end{array}$ & $100 \mathrm{~m}$ & $\begin{array}{l}2006 \\
\quad( \pm 1 \text { year })\end{array}$ & $\begin{array}{c}\text { Remotely sensed } \\
\text { data (SPOT-4/5, } \\
\text { IRS P6 LISS III) }\end{array}$ & $>=85 \%$ & $\begin{array}{l}\text { https://www. } \\
\text { eea.europa.eu/ } \\
\text { data-and- } \\
\text { maps/data/ } \\
\text { clc-2006- } \\
\text { raster-4/ } \\
\text { EEA (2016) }\end{array}$ \\
\hline $\begin{array}{l}\text { GlobCover } \\
2009\end{array}$ & $\begin{array}{l}\text { European Space } \\
\text { Agency } \\
\text { (ESA) }\end{array}$ & $\begin{array}{l}\text { Artificial } \\
\text { Surfaces and } \\
\text { Associated } \\
\text { Areas }\end{array}$ & $300 \mathrm{~m}$ & 2009 & $\begin{array}{c}\text { Remotely sensed } \\
\text { data (MERIS) }\end{array}$ & $69 \%$ & $\begin{array}{l}\text { http://due.esrin. } \\
\text { esa.int/page_- } \\
\text { globcover.php } \\
\text { ESA (2008) }\end{array}$ \\
\hline $\begin{array}{r}\text { GLCNMO } \\
\text { version } 2\end{array}$ & $\begin{array}{l}\text { International } \\
\text { Steering } \\
\text { Committee } \\
\text { For Global } \\
\text { Mapping } \\
\text { (ISCGM) }\end{array}$ & Urban & $500 \mathrm{~m}$ & 2008 & $\begin{array}{l}\text { Population data, } \\
\text { DMSP/OLS } \\
\text { data, ISA data, } \\
\text { MODIS NDVI } \\
\text { data }\end{array}$ & $100 \%$ & $\begin{array}{l}\text { http://www. } \\
\text { iscgm.org/gm/ } \\
\text { glcnmo.html } \\
\text { Tateishi et al. } \\
\text { (2014) }\end{array}$ \\
\hline $\begin{array}{r}\text { GLCNMO } \\
\text { version } 1\end{array}$ & ISCGM & Urban & $1000 \mathrm{~m}$ & 2003 & $\begin{array}{l}\text { Population data, } \\
\text { DMSP/OLS } \\
\text { data, ISA data, } \\
\text { MODIS NDVI } \\
\text { data }\end{array}$ & $84.8 \%$ & $\begin{array}{l}\text { http://www. } \\
\text { iscgm.org/gm/ } \\
\text { glcnmo.html } \\
\text { Tateishi et al. } \\
\text { (2011) }\end{array}$ \\
\hline
\end{tabular}

EO earth observation, COTS commercial off-the-shelf, SPOT systeme pour l'observation de la terre's, IRS Indian remote sensing satellite, MERIS medium resolution imaging spectroradiometer, MODIS moderate resolution imaging spectroradiometer, NDVI normalized difference vegetation index, DMSP/OLS defense meteorological satellite programme's operational line scanner, ISA impervious surface area data

Baur et al. (2015a), including Number of Patches (NumP), Total Edge (TE), Class Area (CA), Percentage of Landscape (PLAND), Mean Patch Size (MPS), Mean Patch Edge (MPE), Edge Density (ED), Patch Density (PD), and Mean patch shape index (MSI). Most of them are considered as 'simple and easily interpretable indices with predictable responses to changes in scale' (Šímová and Gdulová 2012, p. 385).
Some of them significantly correlated with GHG emissions (Baur et al. 2015a). We decided to adopt an excessive number of metrics from those frequently used to quantify urban landscape structure (Wu et al. 2002; Buyantuyev et al. 2010; Schwarz 2010; Ou et al. 2013), including Area-Weighted Mean Shape Index (AWMSI), Mean Patch Fractal Dimension (MPFD), Area-Weighted Mean Patch Fractal Dimension 


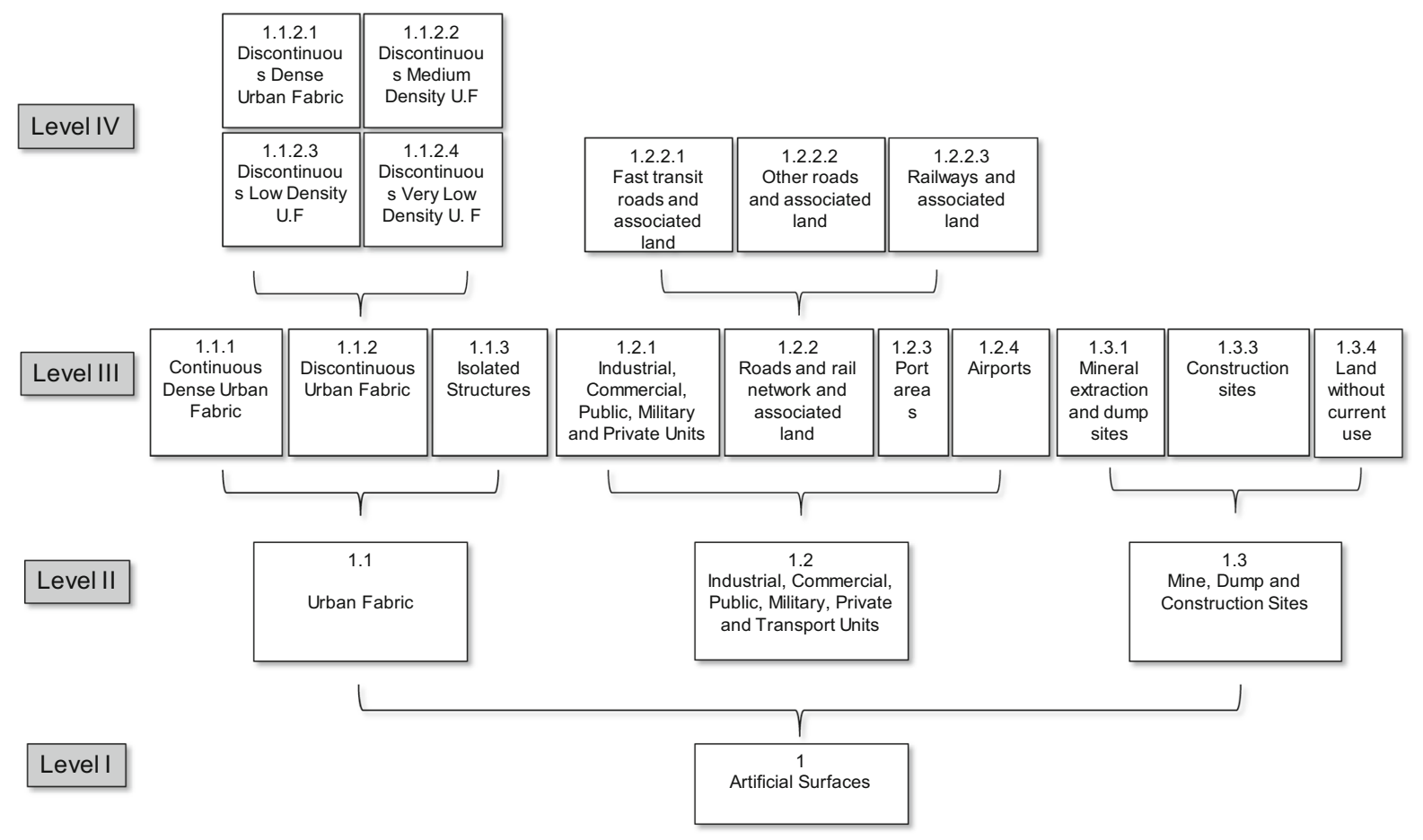

Fig. 1 The four-level hierarchical classification system of urban land use/cover in the Urban Atlas dataset. Green urban areas are excluded from the analyses to facilitate comparison

(AWMPFD), Largest Patch Index (LPI), Patch Size Coefficient of Variation (PSCoV), Patch Size Standard Deviation (PSSD), and Mean Perimeter Area Ratio (MPAR) (see supplementary Table 2 for metric descriptions). Landscape-level metrics were used when multiple ULUC classes were present (i.e., thematic resolution $>1$ ).

We computed landscape metrics for areas within administrative city boundaries because such spatial extents were also used as the basis for the estimations of GHG emissions (Baur et al. 2013). Administrative boundaries were obtained from the Census Units 2011 dataset, a part of the Eurostat's geographical information system 'GISCO' (Eurostat 2015). Landscape metrics were computed using the Patch Analyst package (Rempel et al. 2012) for ArcGIS 10.2 (ESRI 2013).

\section{Scaling analyses}

Thematic and spatial scaling analyses commonly followed two steps. We first computed landscape metrics using the ULUC data for each studied city at with other urban land use/cover datasets. The code for each land use/cover class is adopted from the mapping guide of the Urban Atlas dataset (EEA 2011)

different thematic/spatial scales. We then performed pairwise Pearson's correlation analysis between each resulting landscape metric and per capita GHG emissions, as well as multiple regression analysis, to investigate how these relationships vary with changing thematic/spatial resolution.

\section{Thematic scaling}

Thematic scaling was performed on the basis of the UA dataset that contains information on 20 land use/cover classes. The UA dataset organizes ULUC classes into 4 hierarchies, corresponding to 4 thematic resolutions (Fig. 1). The coarsest thematic resolution has 4 classes including Artificial Surfaces, Agricultural/Semi-natural Areas/Wetlands, Forests, and Water. Only Artificial surfaces, with green urban areas excluded for consistency across all ULUC datasets, were included in the analysis because we focus on man-made components only. Starting from the finest thematic resolution (referred to as Level IV), land use/cover classes were aggregated at three consequent steps to coarser resolutions (i.e., Level 
III, II, and I consequently). The resulting landscape maps were used to calculate the landscape metrics accordingly.

\section{Spatial scaling}

Spatial scale has two inherent dimensions, the grain size (spatial resolution) and the spatial extent. In our study, however, spatial scaling was performed on the basis of grain size only because the spatial extent of each city was fixed within its administrative boundary, where the GHG emissions were estimated. We employed the following two approaches for spatial scaling.

In the first approach, the UA dataset at the fine spatial resolution of $10 \mathrm{~m}$ was used as a basis. It was then sequentially aggregated to the resolutions of 30 , $100,300,500$, and $1000 \mathrm{~m}$, which coincide with resolutions of those selected coarser grained standard ULUC datasets. To this end, the UA data were converted to a binary raster format, distinguishing between urban and non-urban areas. The majority rule (i.e., the type of the coarse-grained output cell is determined by the most dominant type of $10-\mathrm{m}-$ resolution input cells) was used for data aggregation. The resulting maps of urban areas at different spatial resolutions were used to compute landscape metrics. This approach has been adopted by previous scaling studies (e.g., Wu et al. 2002), allowing for systematic analyses of scaling behavior and construction of scalograms (based on correlation coefficient) within a pre-defined spatial scale domain.

In the second approach, we studied the effects of spatial scale by comparing between selected global standard ULUC datasets that are produced at the spatial resolutions of $10,30,100,300,500$, and $1000 \mathrm{~m}$ (Table 1). Doing so, we can investigate the spatial scale effect in a more realistic context, considering that these standard datasets had been frequently used for quantifying landscape patterns worldwide.

Pearson's correlations were used to test the pairwise relationships between single landscape metrics and GHG emissions per capita (one data point for each city, $n=52$ ). Variables were log-transformed, where necessary, to approach normal distributions (Supplementary Tables 3-6). We conducted multiple linear regression and used adjusted $R^{2}$ of full models to assess the overall power of the 16 selected landscape metrics (as explanatory variables) for explaining the
GHG emissions per capita (as response variable) at each studied scale. The multicollinearity between the landscape metrics would not bias the explanatory power (Cohen et al. 2003). We also used linear regression to assess the relative importance of landscape metrics at each studied scale. To reduce uncertainty from single model inference (for instance, inference based on stepwise regression), we used the model averaging technique, which takes into account all possible regression models (Burnham and Anderson 2002). We constructed all possible models with all combinations of the 16 landscape metrics as regressors, and then discarded those with the variance inflation factor $>5$ (considered as strong multicollinearity, which can lead to strongly biased estimation of coefficients, Zuur et al. 2009). The relative importance of a given metric is calculated as the sum of the Akaike weights of models where the metric is included (Burnham and Anderson 2002). Statistical analyses were performed with R 3.3.1 (R Core Team 2016). Model averaging was performed with the $R$ package "MuMIn" (Bartoń 2018).

\section{Results}

Thematic scaling relations

For the 52 studied European cities, we found both significantly positive and negative correlations between per capita GHG emissions and most of the selected landscape metrics at certain thematic resolution(s) of the UA data (Fig. 2). Yet, 3 out of these 16 metrics (i.e., CA, PSSD and MPAR) did not correlate with GHG emissions $(P>0.05)$ at any thematic resolution. For most landscape metrics, the Pearson's $r$ correlation coefficient varied substantially across the 4 thematic resolutions, with the maximum range of up to $\sim 0.6$ (for $L P I$ ). This indicates marked dependence of SERs on thematic resolution.

The comparison between individual landscape metrics revealed three types of scaling relations generally occurring with respect to increasing (i.e., from coarse to fine) thematic resolution. Despite that these types are roughly defined, they can help to demonstrate the essential differences in scaling relations. The first type (hereafter referred to as Type A thematic scaling relation) is characterized by a (close to) monotonic trend, with the strongest correlations 

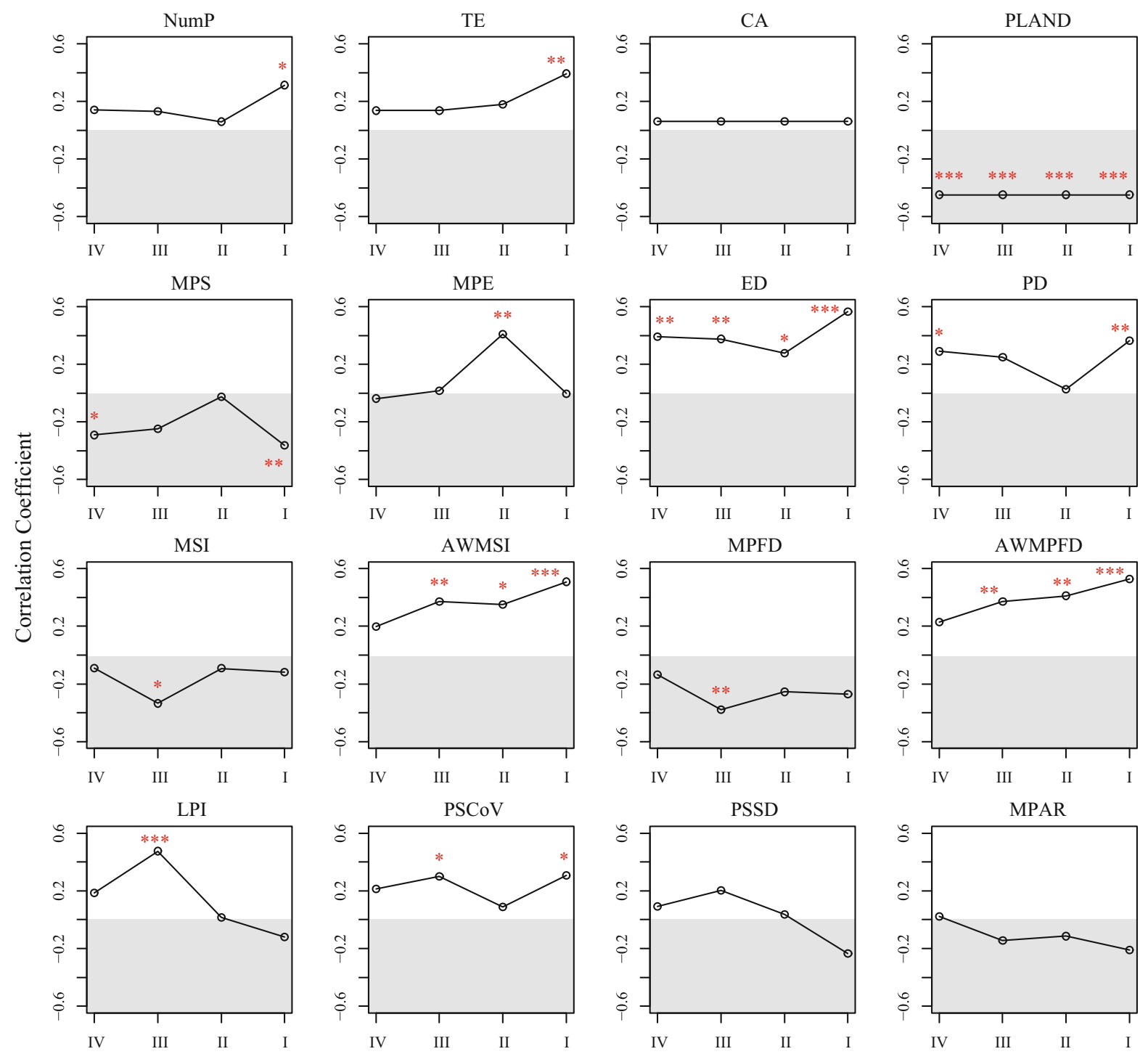

Fine

Coarse

Thematic Level of Urban Atlas data

Fig. 2 Pearson's $r$ correlation coefficient between 16 landscape metrics and per capita GHG emissions at 4 thematic resolutions. I-IV indicate from coarse to fine thematic resolution of the

(measured by the absolute value of correlation coefficient) present at the coarsest (Level I) thematic resolution (including NumP, TE, AWMSI and $A W M P F D$ ). The second type (Type $\mathrm{B}$ thematic scaling relation hereafter) is characterized by a humped or inverse-humped trend, where intermediate (i.e., Level II and III) thematic resolutions presented the strongest (including $M P E, M S I, M P F D$, and $L P I$ ) or weakest
Urban Atlas dataset. Positive versus negative correlations are contrasted by white and gray areas, ${ }^{* * *} P<0.001,{ }^{* * *} P<0.01$, ${ }^{*} P<0.05$

(MPS, ED, PD, and PSCoV) correlations. The third type (Type $\mathrm{C}$ thematic scaling relation hereafter) illustrates a scale-invariant relation ( $C A$ and $P L A N D)$.

Collectively, the power of the 16 selected landscape metrics showed an almost scale-invariant trend at coarser (Levels I-III) thematic resolutions, jointly explaining about $25 \%$ of the between-city variation of GHG emissions. Explained variation sharply 
increased to about $40 \%$ at the finest thematic resolution of Level IV. The relative importance of landscape metrics was also dependent on thematic resolution (Supplementary Fig. 1). For instance, the most important two metrics varied across thematic resolutions: PLAND and LPI (Level IV), PLAND and AWMPFD (Level III), PLAND and MPE (Level II), ED and PLAND (Level I).

\section{Spatial scaling relations}

Our first spatial scaling approach based on the manipulation of spatial resolution revealed a variety of scaling relations (Fig. 3). We observed three types of spatial scaling relations that are analogous to thematic scaling relations. A portion of landscape metrics showed a (close to) monotonic trend with respect to increasing spatial resolution, with strongest correlation found at either the coarsest (including $C A$, $M P S, M P E, P D$, and $L P I$ ) or the finest (including $P L A N D$ and $E D)$ spatial resolutions. We referred to this as Type A spatial scaling relation. In most cases, this type is characterized by gradual trends, but occasionally it exhibited abrupt changes with respect to increasing spatial resolution ( $E D$ and $L P I)$. Another interesting feature is that significantly negative and positive correlations can both occur at the two ends of the scale range (MPS and PD). Type B spatial scaling relation is characterized by a hump-shaped form, with strongest correlations found at the intermediate spatial scales (including MSI, AWMSI, MPFD, AWMPFD, $P S C o V$, and PSSD). Type $\mathrm{C}$ is characterized by (close to) scale-invariant relations, with slight variations $(0.1$ at a maximum) in the correlation coefficient across the observed spatial scales (NumP and TE). The overall explanatory power of 16 landscape metrics showed a Type B scaling trend (Fig. 5b), with the highest found at the $500 \mathrm{~m}$ resolution. The relative importance of landscape metrics showed great dependency on spatial resolution: the most important two metrics were $E D$ and PLAND (10 m resolution), PLAND and LPI (30 m resolution), $P L A N D$ and $P D(100 \mathrm{~m}$ resolution), MPFD and ED (300 m resolution), LPI and PLAND (1000 m resolution), respectively (Supplementary Fig. 2a).

In our second spatial scaling approach, the abovementioned Types A and B spatial scaling relations were also observed for the available standard ULUC datasets (Fig. 4). Compared to the manipulative experiment in the first approach, the scaling relations from these standard datasets generally exhibited more erratic patterns and weaker correlations. Five landscape metrics (CA, MSI, MPFD, PSSD, and MPAR) did not correlate with GHG emissions at any observational spatial scale, and the other 6 metrics (NumP, TE, MPE, AWMSI, AWMPFD, and PSCoV) correlated significantly at only one spatial scale. Similar to the manipulated data in the first scaling approach, the overall explanatory power of the metrics also showed an erratic scaling trend, but the largest explanatory power was found at the $300 \mathrm{~m}$ resolution (Fig. 5c). For the relative importance of landscape metrics, the most important two metrics were $E D$ and PLAND (10 m resolution), PLAND and $L P I$ (30 m resolution), MPAR and PLAND (100 $\mathrm{m}$ resolution), ED and PLAND (300 m resolution), PLAND and MSI (500 m resolution), $E D$ and $L P I$ (1000 m resolution), respectively (Supplementary Fig. 2b), suggesting marked dependency on spatial resolution.

Interestingly, these two scaling approaches can result in largely different SERs and scaling relation for some landscape metrics. For instance, in the first approach, $E D$ was positively correlated with GHG emissions at most spatial scales, whereas the correlation became mostly negative when applied to the standard ULUC datasets, showing apparently different types of scaling trend as well. The overall explanatory power and relative importance of landscape metrics also differed substantially between the two scaling approaches.

\section{Discussion}

Our scaling analyses clearly demonstrated that the observed relationships between urban landscape structure and GHG emissions across the 52 European cities depended on both thematic and spatial resolutions of ULUC data. Strikingly, we did not find consistent scaling relations over the observational scales in the sense that, for different landscape metrics, the SERs can have the largest strength at either coarse, or fine, or intermediate scales across the observational scale range. Characteristic, or intrinsic, scale of a landscape is the level at which the dominant pattern (or the dominant interaction between two spatial structures/ phenomena) emerges, giving rise to stronger correlations between certain pairs of variables (Wu et al. 


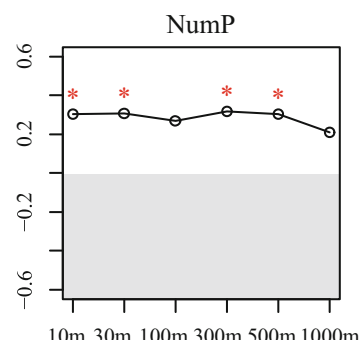

MPS

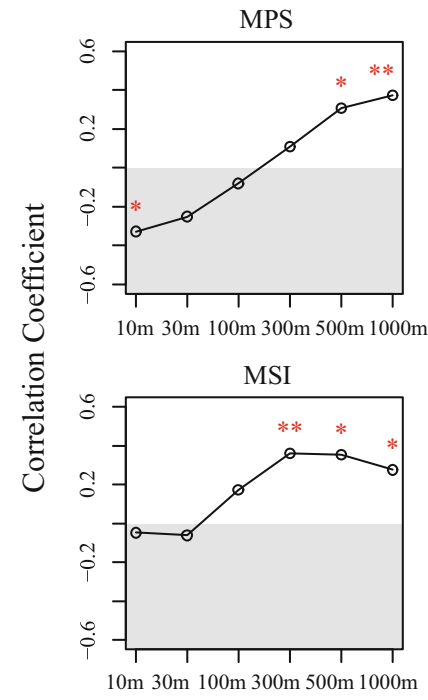

LPI

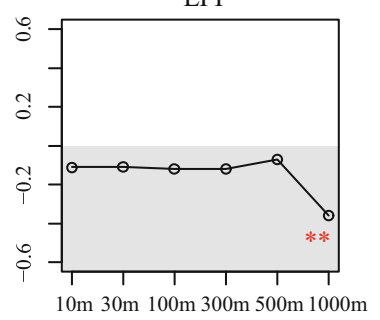

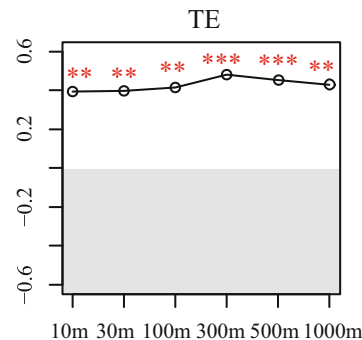

MPE

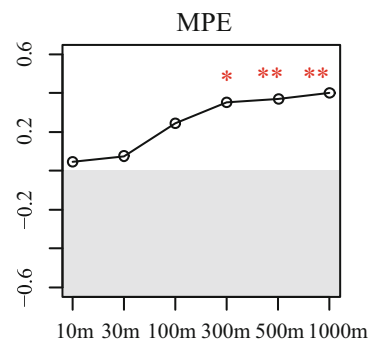

AWMSI

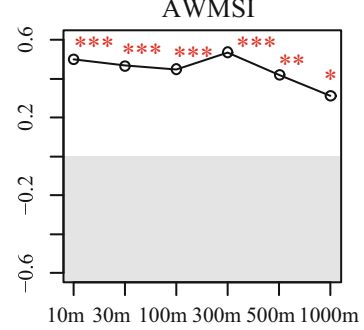

PSCoV

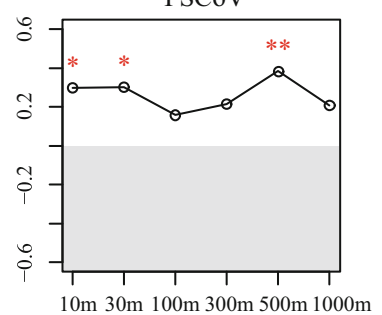

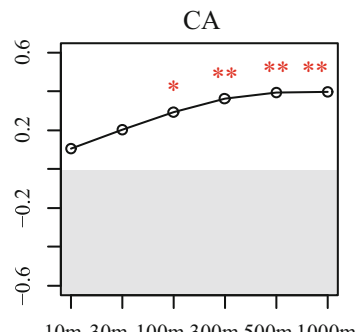

$10 \mathrm{~m} 30 \mathrm{~m} 100 \mathrm{~m} 300 \mathrm{~m} 500 \mathrm{~m} 1000 \mathrm{~m}$

ED

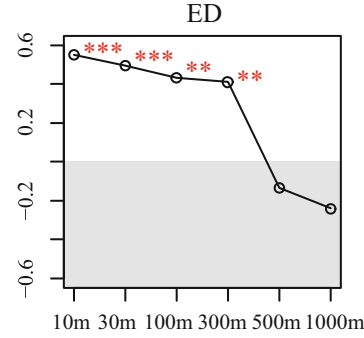

MPFD

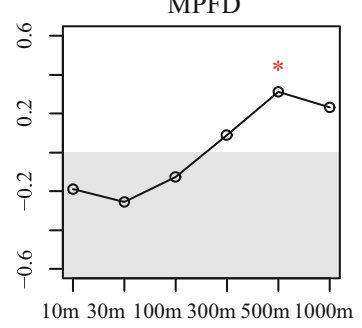

PSSD

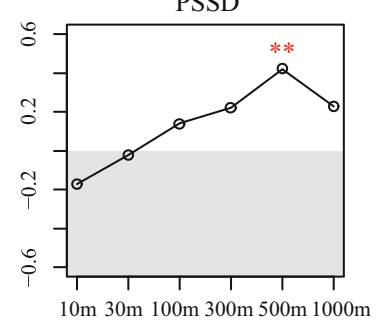

PLAND

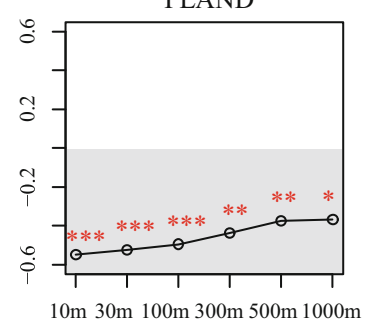

PD

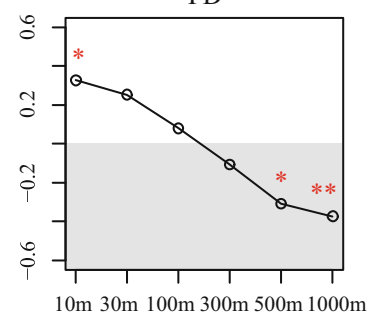

AWMPFD

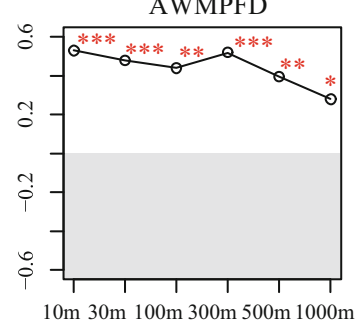

MPAR

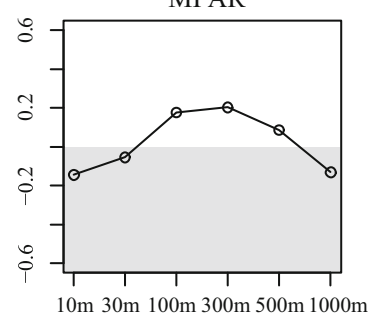

Fine

Spatial Resolution of Urban Atlas data

Fig. 3 Pearson's $r$ correlation coefficients between 16 landscape metrics and per capita GHG emissions at different grain sizes based on the resampled resolutions of the Urban Atlas data.

2006; Buyantuyev et al. 2010; Xu et al. 2012). Such characteristic scales are often recognized as optimal scales for quantifying landscape patterns or patternprocess relationships (urban spatial structure vs. GHG emissions in our case). Our results suggest that within the studied scale domain, there were no consistently 'optimal' thematic or spatial scales for quantifying SERs based on the selected set of landscape metrics. For each studied city, the GHG emission has a fixed value for different thematic/
Positive versus negative correlations are contrasted by white and gray areas, ${ }^{* * *} P<0.001,{ }^{* *} P<0.01,{ }^{*} P<0.05$

spatial resolutions, leaving scale dependence of landscape metrics as the direct explanation for the scale dependence of SERs.

The effect of thematic resolution on landscape pattern and processes has been increasingly recognized during the past ten years (Bailey et al. 2007a, b; Buyantuyev and Wu 2007; Buyantuyev et al. 2010; Zhou et al. 2014). Previous systematic thematic scaling analyses have shown that many landscape metrics present monotonically increasing, decreasing, 


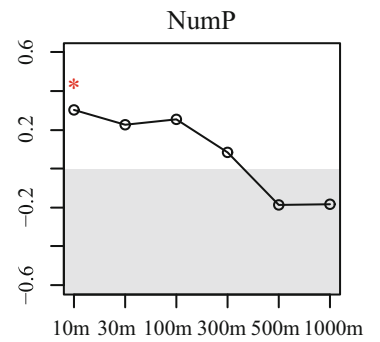

MPS
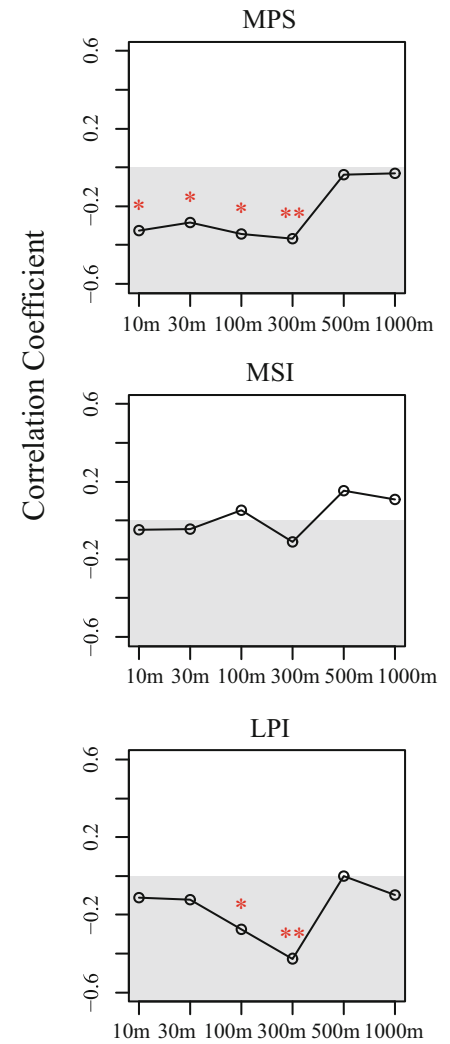

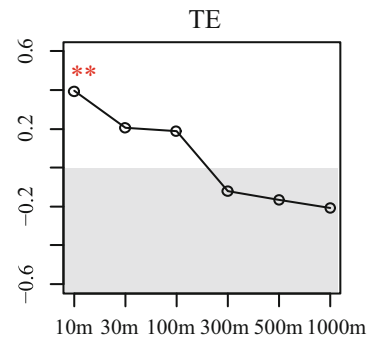

MPE

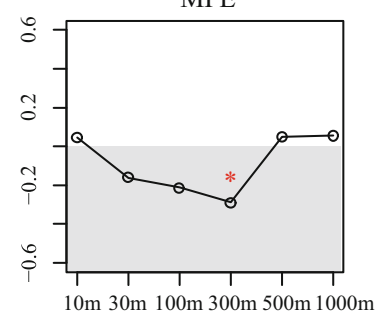

AWMSI
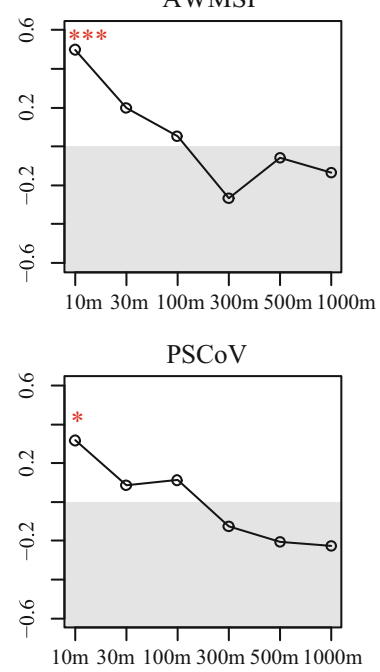

CA

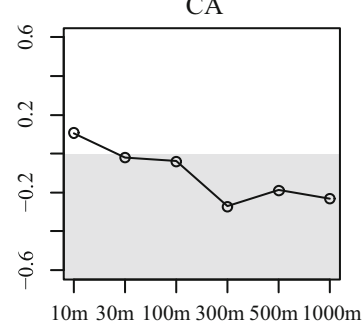

ED

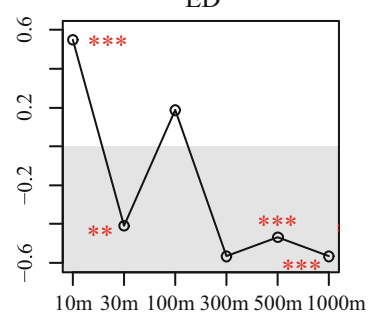

MPFD
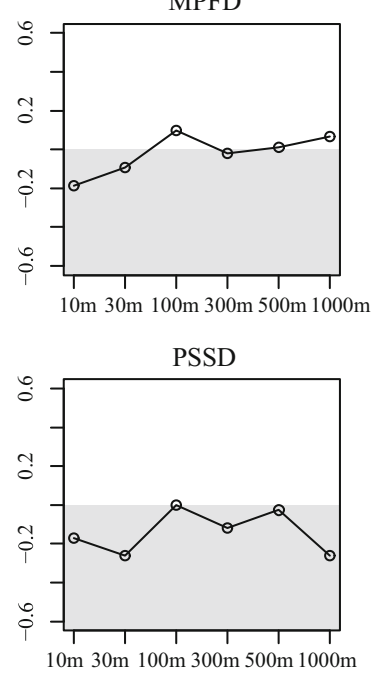

PLAND

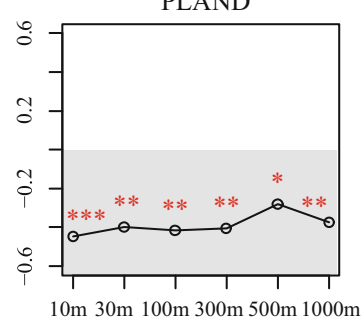

PD

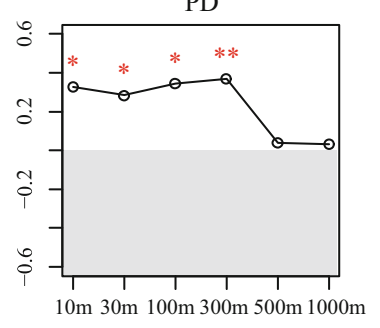

AWMPFD
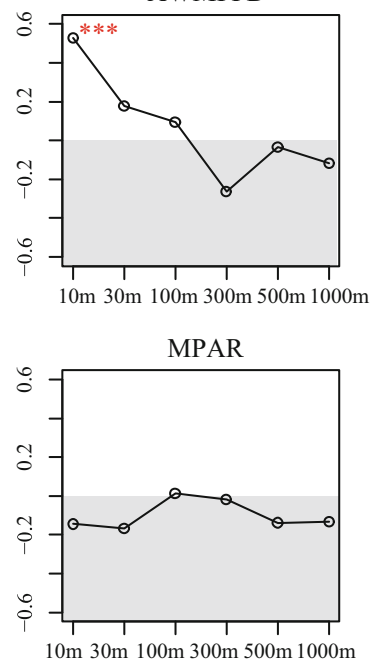

Fine

Coarse

SpatialResolutionofsixLandUseandLandCoverdatasets

Fig. 4 Pearson's $r$ correlation coefficients between 16 landscape metrics and per capita GHG emissions at different spatial scales based on available standard land use/cover datasets.

or humped behaviors with respect to increasing thematic resolution (Buyantuyev and $\mathrm{Wu} 2007$; Buyantuyev et al. 2010). Furthermore, it has been shown that strong correlations between landscape metrics and physical (Zhou et al. 2014), biological (Bailey et al. 2007a, b), and socioeconomic (Buyantuyev et al. 2010) variables can arise at a variety of thematic resolutions, suggesting that various landscape processes that interact with different facets of
Positive versus negative correlations are contrasted by white and gray areas, ${ }^{* * * *} P<0.001,{ }^{* *} P<0.01,{ }^{*} P<0.05$

landscape structure can be better reflected by correspondingly different classification schemes and thematic resolutions of landscape maps. In our study, we also observed such diverse thematic scaling behaviors of SERs, indicating that complexity can arise from even a single specific landscape variable, such as GHG emissions, in response to variation of thematic resolution. The scale-invariant behavior of $C A$ and $P L A N D$ can be explained by the fact that these two metrics 
Fig. 5 Collective power of 16 landscape metrics in explaining between-city variation of per capita GHG emissions at different thematic (a) and spatial (b, c) scales. Explanatory power is measured by adjusted $R^{2}$ of multiple regression models with landscape metrics as independent variables and GHG emission as the dependent variable. ${ }^{* * *} P<0.001,{ }^{* *} P<0.01$, ${ }^{*} P<0.05$
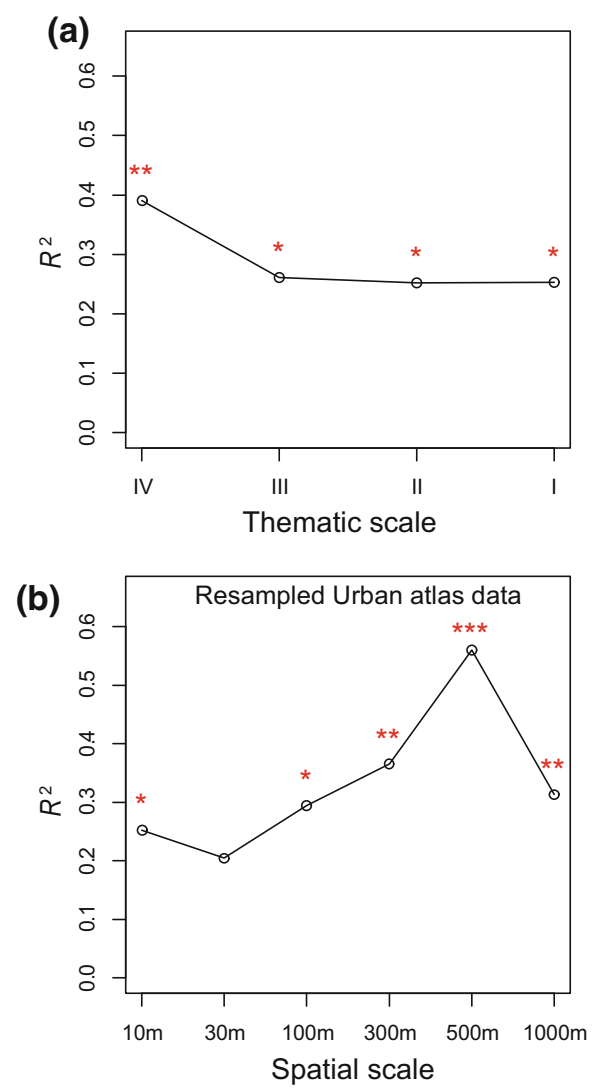

measuring, respectively, absolute and relative city size remain constant at any thematic resolution. It makes intuitive sense that the strongest collective explanatory power of landscape metrics was observed at the finest thematic resolution. GHG emissions are associated with specific urban functioning in human daily life. Finer land use/cover classification schemes can well distinguish between these functioning, therefore, better capture the link with GHG emissions.

In line with previous spatial scaling analyses of real and contrived landscapes (Wu et al. 2002; Shen et al. 2004; Wu 2004), we found monotonic, humped, and invariant behaviors with respect to increasing spatial scale. Despite the agreement, our results had some major differences from previous studies. In contrast to the previous finding that different scaling relations could be attributed to different categories of landscape metrics (e.g., compositional vs. shape metrics) (Bailey et al. 2007a, b), a surprising finding here is that confounding trends can be sometimes detected even for landscape metrics that are intentionally used to measure same structural attributes. For example, very similar shape metrics, such as $M S I$ vs. AWMSI and $M P F D$ vs. $A W M P F D$, had contrasting (negative vs. positive) correlations with GHG emissions, and very different thematic scaling relations (monotonic vs. humped). This suggests that SERs are rather metricsensitive. Another surprising finding is that opposite, but both significant, correlations can be observed at the coarsest and finest spatial resolutions. This may imply that there exists more than one characteristic scale in the system, corresponding with different interactions between urban spatial structure and GHG distribution at these scales. While the scaling behaviors of some simple and easily interpretable landscape metrics can be well understood (for example, with coarsening spatial resolution, small patches would merge into larger ones with more simplified shapes in general, resulting in lower values of NumP and TE, Wu et al. 2002; Wu 2004; Šímová and Gdulová 2012), metric-emission association showed more complicated scaling trends, which are beyond our speculation. 
The spatial scaling issue appears even more complex when it comes to available standard ULUC data. First, spatial scaling relations fluctuated significantly and unpredictably. Second, the standard and manipulated data could manifest very different (e.g., positive vs. negative) SERs and scaling behaviors for same landscape metrics. The generation of standard ULUC datasets often involves a variety of geospatial data (remotely sensed data, topographic maps, navigation data, census data, etc.) with different minimum mapping units, which could have significant influences on behaviors of landscape metrics (Šímová and Gdulová 2012). Such confounding factors related to ULUC data production practices may partly explain why we could not observe a coherent spatial scaling trend. However, detailed information on these confounding factors are often lacking, hindering further analyses on their role in influencing the scaling trends. In addition, accuracy of the ULUC data is likely playing an important role in causing these perplexing patterns. When cascading to a series of intricate analyses, even small errors in remote sensing products could be largely amplified and lead to biased results (e.g., $\mathrm{Xu}$ et al. 2015). Referring to the simplest common metric of overall classification accuracy, most datasets used in our study have accuracies for urban areas higher than the generally accepted threshold of 85\% (Thomlinson et al. 1999; Congalton and Green 2009). However, this may not be sufficient for eliminating uncertainties in the resulting SERs, calling attention to in-depth sensitivity analyses in future studies.

It has been well recognized that landscape metrics and scale can give rise to a series of complex issues in characterization of landscape pattern, as well as pattern-process relationships (Tischendorf 2001; Li and $\mathrm{Wu} 2004)$. Our work highlights such complexities associated with SERs, calling attention to the importance of estimation of uncertainties that need to be recognized by practitioners engaged in drafting urban planning policies towards GHG mitigation. To reduce uncertainties in our understanding of SERs, further studies need to address both socioeconomic and spatial driving mechanisms of urban GHG emissions, ideally in combination with fine-scale spatial data of GHG emissions. More in-depth analyses focusing on both thematic and spatial scales (for instance, perform scaling analyses on all thematic resolutions) should facilitate a more comprehensive understanding. It is also necessary to quantify SERs for other regions to ascertain whether the observed scaling relations are specific to Europe. One important caveat should not be forgotten while conducting such analyses: spatial and thematic scales are inter-related, in the sense that modifying one may often inadvertently affect the other. For example, finer thematic resolution would often require finer spatial resolution to be able to depict classes characterized by small patches. Also, increasing/decreasing thematic resolution may result in patch coalesces and other unpredictable arrangement of patches.

In summary, despite the consensus on positive effects of compact spatial structure of urban areas on mitigating GHG emissions, our results demonstrate that detection of such effects is highly sensitive to spatial and thematic resolutions of landscape data, thus providing justification for multi-scale approaches in further studies quantifying SERs. Important caveats should be taken when it comes to interpretations based on single landscape metrics. Particular consideration may be given to those metrics that are easily interpretable, have predictable scaling behaviors (in terms of metric response to scale, as well as their resulting SERs response to scale), and are possibly important for shaping SERs. PLAND, ED, and LPI among some others are found to have all those qualities. Metrics that could lead to contradictory scaling relations (e.g., MSI, AWMSI, MPFD, and $A W M P F D$ ) should be used with caution or avoided. It is imperative to quantify SERs over theoretically and practically meaningful ranges of spatial/thematic scales that allow for a systematic investigation on scaling behaviors and detection of characteristic scales. These are essential for exploratory analyses of SERs, because arbitrary selection of metrics and scales can easily lead to biased conclusions. Overall, our work suggests that there is no simple answer to the question 'What are the optimal thematic/spatial scales?' in this context. Inappropriate cross-scale extrapolation of statistical relationships may cause the so-called problem of 'ecological fallacy' (Openshaw and Taylor 1979; Wu 2004).

Acknowledgements We thank three anonymous reviewers for their valuable comments to an earlier version of this manuscript. C.X. thanks Yiqing Xu for his great inspiration. This study is supported by The National Key R\&D Program of China (2017YFC0506200), National Natural Science 
Foundation of China (31770512), and the Fundamental Research Funds for the Central Universities (020814380089).

Open Access This article is distributed under the terms of the Creative Commons Attribution 4.0 International License (http:// creativecommons.org/licenses/by/4.0/), which permits unrestricted use, distribution, and reproduction in any medium, provided you give appropriate credit to the original author(s) and the source, provide a link to the Creative Commons license, and indicate if changes were made.

\section{References}

Anderson WP, Kanaroglou PS, Miller EJ (1996) Urban form, energy and the environment: a review of issues, evidence and policy. Urban Stud 33(1):7-35

Bailey D, Billeter R, Aviron S, Schweiger O, Herzog F (2007a) The influence of thematic resolution on metric selection for biodiversity monitoring in agricultural landscapes. Landscape Ecol 22(3):461-473

Bailey D, Herzog F, Augenstein I, Aviron S, Billeter R, Szerencsits E, Baudry J (2007b) Thematic resolution matters: indicators of landscape pattern for European agroecosystems. Ecol Ind 7(3):692-709

Bartoń K (2018) MuMIn: multi-model inference. R package version 1.40.4. https://CRAN.R-project.org/package= MuMIn. Accessed March 2018

Baur AH, Förster M, Kleinschmit B (2015a) The spatial dimension of urban greenhouse gas emissions: analyzing the influence of spatial structures and LULC patterns in European cities. Landscape Ecol 30(7):1195-1205

Baur AH, Lauf S, Förster M, Kleinschmit B (2015b) Estimating greenhouse gas emissions of European cities-modeling emissions with only one spatial and one socioeconomic variable. Sci Total Environ 520:49-58

Baur AH, Thess M, Kleinschmit B, Creutzig F (2013) Urban climate change mitigation in Europe: looking at and beyond the role of population density. J Urban Plann Dev 140(1):04013003

Borrego C, Martins H, Tchepel O, Salmim L, Monteiro A, Miranda AI (2006) How urban structure can affect city sustainability from an air quality perspective. Environ Modell Softw 21(4):461-467

Burnham KP, Anderson DR (2002) Model selection and multimodel inference: a practical information-theoretical approach. J Wildl Manag 67(3):175-196

Buyantuyev A, Wu J (2007) Effects of thematic resolution on landscape pattern analysis. Landscape Ecol 22(1):7-13

Buyantuyev A, Wu J, Gries C (2010) Multiscale analysis of the urbanization pattern of the Phoenix metropolitan landscape of USA: time, space and thematic resolution. Landscape Urban Plann 94(3):206-217

Chen X, Cao X, Liao A, Chen L, Peng S, Lu M, Chen J, Zhang W, Zhang H, Han G, Wu H (2016) Global mapping of artificial surfaces at 30-m resolution. Sci China Earth Sci 59(12):2295-2306

Chen J, Chen J, Liao A, Cao X, Chen L, Chen X, He C, Han G, Peng S, Lu M, Zhang W (2015) Global land cover mapping at $30 \mathrm{~m}$ resolution: a POK-based operational approach. ISPRS J Photogramm Remote Sens 103:7-27

Chen Y, Li X, Zheng Y, Guan Y, Liu X (2011) Estimating the relationship between urban forms and energy consumption: a case study in the Pearl River Delta, 2005-2008. Landscape Urban Plann 102(1):33-42

Cohen J, Cohen P, West SG, Aiken LS (2003) Applied multiple regression/correlation analysis for the behavioral sciences, 3rd edn. Lawrence Erlbaum Associates, Hillsdale, NJ

Congalton RG, Green K (2009) Assessing the accuracy of remotely sensed data: principles and practices, 2nd edn. CRC Press, Boca Raton, FL

Crowley TJ (2000) Causes of climate change over the past 1000 years. Science 289(5477):270-277

Dhakal S (2010) GHG emissions from urbanization and opportunities for urban carbon mitigation. Curr Opin Environ Sustain 2(4):277-283

EEA (European Environmental Agency) (2010) Urban Atlas. https://www.eea.europa.eu/data-and-maps/data/urbanaCAs. Accessed July 2016

EEA (European Environmental Agency) (2011) Mapping Guide for a European Urban Atlas. https://www.eea.europa.eu/ data-and-maps/data/urban-atlas/mapping-guide/urban_ atlas_2006_mapping_guide_v2_final.pdf. Accessed July 2016

EEA (European Environmental Agency) (2016) Corine Land Cover 2006 raster data. https://www.eea.europa.eu/dataand-maps/data/clc-2006-raster-4/. Accessed July 2017

ESA (European Space Agency) (2008). Global Land Cover Product (2005-06). Available from http://due.esrin.esa.int/ page_globcover.php (accessed July 2016)

ESRI (2013) ArcGIS Desktop 10.2. Environmental Systems Resource Institute, Redlands, CA

Eurostat (2015) Census units 2011. http://ec.europa.eu/eurostat/ web/gisco/geodata/reference-data/administrative-unitsstatistical-units/census\#censusunits11. Accessed July 2016

Field CB, Barros VR (eds) (2014) Climate change 2014: impacts, adaptation, and vulnerability. Cambridge University Press, Cambridge and New York.

Hoornweg D, Bhada P, Freire M, Trejos C, Sugar L (2010) Cities and climate change: an urgent agenda. The World Bank, Washington, DC

Lee S, Lee B (2014) The influence of urban form on GHG emissions in the US household sector. Energy Policy 68:534-549

Li H, Wu J (2004) Use and misuse of landscape indices. Landscape Ecol 19(4):389-399

Li H, Wu J (2006) Uncertainty analysis in ecological studies: an overview. In: Wu J, Jones $\mathrm{KB}, \mathrm{Li} \mathrm{H}$, Loucks $\mathrm{O}$ (eds) Scaling and uncertainty analysis in ecology. Springer, New York

Liu Z, He C, Zhou Y, Wu J (2014) How much of the world's land has been urbanized, really? A hierarchical framework for avoiding confusion. Landscape Ecol 29(5):763-771

Makido Y, Dhakal S, Yamagata Y (2012) Relationship between urban form and $\mathrm{CO} 2$ emissions: evidence from fifty Japanese cities. Urban Clim 2:55-67

Martins H (2012) Urban compaction or dispersion? an air quality modelling study. Atmos Environ 54(4):60-72

Melillo JM, Richmond TC, Yohe GW (2014) Climate change impacts in the United States: the third national climate 
assessment. US Global Change Research Program, Washington, DC

Newman PW, Kenworthy JR (1989) Gasoline consumption and cities. J Am Plann Assoc 55(1):24-37

Norman J, MacLean HL, Kennedy CA (2006) Comparing high and low residential density: life-cycle analysis of energy use and greenhouse gas emissions. J Urban Plann Dev 132(1):10-21

Openshaw S, Taylor PJ (1979) A million or so correlation coefficients: three experiments on the modifiable areal unit problem. Stat Appl Spat Sci 21:127-144

Ou J, Liu X, Li X, Chen Y (2013) Quantifying the relationship between urban forms and carbon emissions using panel data analysis. Landscape Ecol 28(10):1889-1907

Pachauri RK, Allen MR, Barros VR, Broome J, Cramer W, Christ R, Church JA, Clarke L, Dahe Q, Dasgupta P, Dubash NK (2014) Climate change 2014: synthesis Report. Contribution of working groups I, II and III to the fifth assessment report of the intergovernmental panel on climate change. IPCC, p 151

R Core T (2016) R: a language and environment for statistical computing

Rempel RS, Kaukinen D, Carr AP (2012) Patch analyst and patch grid. Ontario Ministry of Natural Resources. Centre for Northern Forest Ecosystem Researc, Thunder Bay, ON

Rodríguez MC, Dupont-Courtade L, Oueslati W (2016) Air pollution and urban structure linkages: evidence from European cities. Renew Sustain Energy Rev 53:1-9

Saura S, Martinez-Millan J (2001) Sensitivity of landscape pattern metrics to map spatial extent. Photogramm Eng Remote Sens 67(9):1027-1036

Schwarz N (2010) Urban form revisited-selecting indicators for characterising European cities. Landscape Urban Plann 96(1):29-47

Shao G, Liu D, Zhao G (2001) Relationships of image classification accuracy and variation of landscape statistics. Can J Remote Sens 27(1):33-43

Shen W, Darrel JG, Wu J, Gardner H, Gardner RH (2004) Evaluating empirical scaling relations of pattern metrics with simulated landscapes. Ecography 27(4):459-469

Š́mová P, Gdulová K (2012) Landscape indices behavior: a review of scale effects. Appl Geogr 34:385-394
Tateishi R, Hoan NT, Kobayashi T, Alsaaideh B, Tana G, Phong DX (2014) Production of global land cover dataGLCNMO2008. J Geogr Geol 6(3):99

Tateishi R, Uriyangqai B, Al-Bilbisi H, Ghar MA, Tsend-Ayush J, Kobayashi T, Kasimu A, Hoan NT, Shalaby A, Alsaaideh B, Enkhzaya T (2011) Production of global land cover data-GLCNMO. Int J Digital Earth 4(1):22-49

Thomlinson JR, Bolstad PV, Cohen WB (1999) Coordinating methodologies for scaling landcover classifications from site-specific to global: steps toward validating global map products. Remote Sens Environ 70(1):16-28

Tischendorf L (2001) Can landscape indices predict ecological processes consistently? Landscape Ecol 16(3):235-254

Turner MG, O’Neill RV, Gardner RH, Milne BT (1989) Effects of changing spatial scale on the analysis of landscape pattern. Landscape Ecol 3(3-4):153-162

Wu J (2004) Effects of changing scale on landscape pattern analysis: scaling relations. Landscape Ecol 19(2):125-138

Wu J, Jelinski DE, Luck M, Tueller PT (2000) Multiscale analysis of landscape heterogeneity: scale variance and pattern metrics. Geogr Inform Sci 6(1):6-19

Wu J, Jones B, Li H, Loucks OL (2006) Scaling and uncertainty analysis in ecology: methods and applications. Ecology 88(1):267-268

Wu J, Shen W, Sun W, Tueller PT (2002) Empirical patterns of the effects of changing scale on landscape metrics. Landscape Ecol 17(8):761-782

Xu C, Holmgren M, Van Nes EH, Hirota M, Chapin FS III, Scheffer M (2015) A changing number of alternative states in the boreal biome: reproducibility risks of replacing remote sensing products. PLoS ONE 10(11):e0143014

Xu C, Liu M, Hong C, Chi T, An S, Yang X (2012) Temporal variation of characteristic scales in urban landscapes: an insight into the evolving internal structures of China's two largest cities. Landscape Ecol 27(7):1063-1074

Zhou W, Qian Y, Li X, Li W, Han L (2014) Relationships between land cover and the surface urban heat island: seasonal variability and effects of spatial and thematic resolution of land cover data on predicting land surface temperatures. Landscape Ecol 29(1):153-167

Zuur AF, Leno EN, Walker NJ, Aiken LS (2009) Mixed effects models and extensions in ecology with R. Springer, New York 